УДК 612.393.2+615.272.014.425]:543.852

\title{
ВЛИЯНИЕ ФЕРМЕНТАЦИИ И ИЗМЕНЕНИЯ КИСЛОТНОСТИ СРЕДЫ НА СОСТАВ И АНТИОКСИДАНТНУЮ АКТИВНОСТЬ ВОДНЫХ ЭКСТРАКТОВ ЧАЯ
}

\author{
(C) Е.И. Рябинина", Е.Е. Зотова, Н.И. Пономарева, О.А. Мезенцева, М.А. Булгакова
}

Воронежская государственная медицинская академия им. Н.Н. Бурденко, ул. Студенческая, 10, Воронеж, 394036 (Россия), e-mail: ryabinina68@mail.ru

Потенциометрическим методом установлено, что зеленый чай содержит гидролизуемые дубильные вещества, а черный - гидролизуемые и конденсированные, последние составляют примерно $70 \%$ от суммарного содержания. Амперометрическим методом измерена антиоксидантная активность экстрактов чая с различным типом ферментации, наивысшими показателями обладают образцы зеленого чая. Выявлена корреляционная связь между суммарным содержанием полифенолов в чае и антиоксидантной активностью. Установлено, что при уменьшении рН снижается количество танинов, участвующих в окислительных процессах, что может быть связно с переходом их в неионизированную форму.

Ключевые слова: антиоксидантная активность, полифенолы, потенциометрический и амперометрический методы, чай.

\section{Введение}

Одним из наиболее популярных напитков следует считать чай, который употребляют в виде свежезаваренного напитка, приготовленного традиционным для разных стран и народов способом. Чай употребляют не только для бодрости и восстановления работоспособности организма, восполнения энергии и согревания, но и для поддержания нормальной физиологической деятельности важных систем организма человека: сердечно-сосудистой, пищеварительной, иммунной и особенно антиоксидантной.

Именно антиоксидантная система регулирует в организме концентрацию свободных радикалов, в том числе образующихся в избыточном количестве при воздействии на организм таких факторов, как стресс, радиация, курение, некачественные продукты и др.

Нас как потребителей чая интересует прежде всего вопрос о пользе или вреде пищевого продукта, а это определяется в первую очередь химическими веществами, которые содержатся в чайном напитке. Ведь именно растворимая часть чая поступает в организм человека. Из растворимых веществ следует обратить внимание на пять самых важных: дубильные вещества, эфирные масла, алкалоиды, аминокислоты и витамины. При этом следует отметить, что многие из них признаны эффективными антиоксидантами, потребность в которых увеличивается с возрастом, так как эндогенная антиоксидантная система человека уже с 30 лет начинает заметно уменьшать свою функциональную активность, а следовательно, начинает проявляться свободно радикальная патология (синдром пероксидации).

За последнее время появились многочисленные публикации, подтверждающие полезные свойства чая,

Рябинина Елена Ивановна - доцент кафедры химии, кандидат химических наук, тел.: (4732)73-60-48, e-mail: ryabinina68@mail.ru

Зотова Елена Евгеньевна - старший преподаватель кафедры химии, кандидат химических наук

Пономарева Наталия Ивановна - заведующая кафедрой химии, доктор химических наук, профессор

Мезенцева Ольга Александровна - студентка

Булгакова Мария Александровна - студентка которые заключаются в предотвращении и подавлении онкологических заболеваний и значительном снижении риска развития атеросклероза, болезни Паркинсона, - вызванных пероксидацией [1-3].

Дубильные вещества - один из существенных компонентов чайного напитка. Они представляют собой сложную смесь более трех десятков полифенольных соединений (танинов, катехинов и их производных).

\footnotetext{
* Автор, с которым следует вести переписку.
} 
Дубильные вещества, входящие в состав водных экстрактов различных сортов чая, по классификации К. Фрейденберга, делятся на две группы: гидролизуемые и конденсированные [4]. Дубильные вещества чая не остаются неизменными. Продукты их окисления - хиноны, возникающие в ходе фабричного производства чая, в свою очередь, производят окисление других веществ чайного листа и образуют ароматические и пигментные продукты чая, что приводит к изменению не только состава ферментированного чая, но и его антиоксидантной активности.

Цель настоящей работы - определение содержания дубильных веществ в экстрактах чая с различным типом ферментации, установление их природы и антиоксидантной активности в зависимости от рН среды.

\section{Экспериментальная часть}

В качестве объекта исследования выбраны следующие сорта чая: зеленый: «Јaf tеа» (цейлонский), «Tess style» (китайский); черный: «AKBAR» (цейлонский), «Assam» (индийский).

Водный чайный экстракт готовился путем нагревания 1,5 г чая со 100 мл воды на водяной бане с обратным холодильником в течение 20 мин. Обнаружение отдельных групп танинов в исследуемых чаях проводили с помощью качественных реакций [4], а количественное - потенциометрическим методом [5-6]. Процентное содержание дубильных веществ рассчитывали по формуле:

$$
X=\frac{V_{1} \cdot K \cdot D \cdot V \cdot 100 \cdot 100}{V_{2} \cdot(100-W) \cdot m}
$$

где $V_{l}$ - объем 0,02 $\mathrm{M} \mathrm{KMnO}_{4}$, пошедшего на титрование, мл; $V_{2}$ - объем экстракта, взятого для титрования, мл; $K$ - поправка на титр (по щавелевой кислоте); $D$ - коэффициент пересчета на танин: для гидролизуемых дубильных веществ равен 0.004157, для конденсированных - 0,00582; $V$ - общий объем экстракта, мл; $m$ - масса навески сырья, г; $W$ - влажность, $\%$.

Ошибка эксперимента не превышала $5 \%$.

Антиоксидантную активность экстрактов оценивали амперометрическим методом на приборе «Цвет Яуза-01-АА» [8]. Сущность данного метода заключается в измерении электрического тока, возникающего при окислении исследуемого вещества (или смеси веществ) на поверхности рабочего электрода при определенном потенциале. При этом потенциале происходит окисление только групп -ОН природных антиоксидантов фенольного типа. Сигнал регистрируется в виде дифференциальных выходных кривых. С помощью специального программного обеспечения производили расчет площадей пиков (дифференциальных кривых) анализируемого и стандартного веществ. Для анализа использовали среднее значение 4-5 измерений. В качестве стандартного вещества применяли общеизвестный антиоксидант кверцетин. Предварительно строили градуировочную зависимость сигнала образца сравнения (кверцетина) от его концентрации $\left(0,2 ; 0,5 ; 1,0 ; 4,0\right.$ мг/дм $\left.{ }^{3}\right)$. Рабочий раствор кверцетина с концентрацией 100 мг/дм ${ }^{3}$ готовили по общепринятой методике [9]. С помощью полученной градуировки рассчитывали содержание антиоксидантов в исследуемых образцах в единицах концентрации кверцетина. Расчет антиоксидантной активности (АОА, мг/г) исследуемого образца проводили по формуле:

$$
A O A=\frac{C A \cdot V \cdot N}{m \cdot 1000}
$$

где $C A$ - величина антиоксидантной активности кверцетина, соответствующая его концентрации по калибровочному графику, мг/дм ${ }^{3} ; V$ - объем анализируемой пробы, см $^{3} ; m$ - навеска анализируемого вещества, г; $N$ - разбавление анализируемого образца.

Стандартное отклонение последовательных измерений анализируемых проб не превышало $3 \%$. 


\section{Результаты и обсуждение}

На основании проведенных качественных реакций на дубильные вещества установлено, что исследуемые образцы зеленого чая содержат гидролизуемые танины, а экстракты черного чая смешанную группу - гидролизуемые и конденсированные.

Количественное содержание разных групп танинов в исследуемых настоях чая определено потенциометрическим методом. На рисунке 1 представлены дифференциальные кривые потенциометрического титрования. В экстрактах черного чая, в отличие от зеленого, наблюдается два максимума, что характеризует наличие двух окислительно-восстановительных процессов. Поскольку в водном экстракте черного чая присутствуют обе группы танинов (гидролизуемые и конденсированные), то наблюдаемые максимумы отвечают окислению разных групп полифенолов. В работах $[6,7]$ было доказано, что первый максимум отвечает окислению гидролизуемых танинов, а второй - конденсированных. Отсчет по оси абсцисс, соответствующий первому максимуму, дает объем титранта, израсходованного на титрование гидролизуемых танинов. Объем точки эквивалентности второго пика соответствует суммарному объему перманганата калия, идущего на окисление разных групп полифенолов в экстрактах черного чая. По разнице объемов второго и первого максимума определяли объем титранта, затраченного на окисление конденсированных танинов. Исходя из полученных данных рассчитано процентное содержание дубильных веществ в водных экстрактах чая, результаты представлены в таблице.

В образцах зеленого чая содержание гидролизуемых танинов варьируется в количестве 6,4-6,87\%. Содержание танинов в образцах черного чая изменяется в пределах 4,18-5,01\%, из которых 1,3-1,55\% гидролизуемые, 2,88-3,5\% конденсированные. Таким образом, в черном чае конденсированные танины составляют наибольшую часть - примерно 70\% от суммарного содержания. Конденсированные танины образуются при полимеризации катехинов, лейкоантоцианидов и других восстановленных форм флавоноидов. Образование танинов происходит как в самом растении в процессе биосинтеза, так и при технологической обработке (ферментации).

Поскольку реальные объекты представляют собой довольно сложные по химическому составу системы, то проблемой практического использования антиоксидантов растительного происхождения является количественная оценка их антиоксидантной активности, которая реализуется за счет суммарного содержания и действия восстановителей различной природы.

Рис. 1. Дифференциальные кривые потенциометрического титрования перманганатом калия ( $V$ - прибавленного $\mathrm{KMnO}_{4}, \Delta V$ - объем очередной порции $\mathrm{KMnO}_{4}, \Delta E$ - изменение потенциала, вызванного прибавлением одной порции $\mathrm{KMnO}_{4}$ ) водных экстрактов чая: 1 - Jaf tea; 2 - Tess style; 3 - AKBAR; 4 - Assam

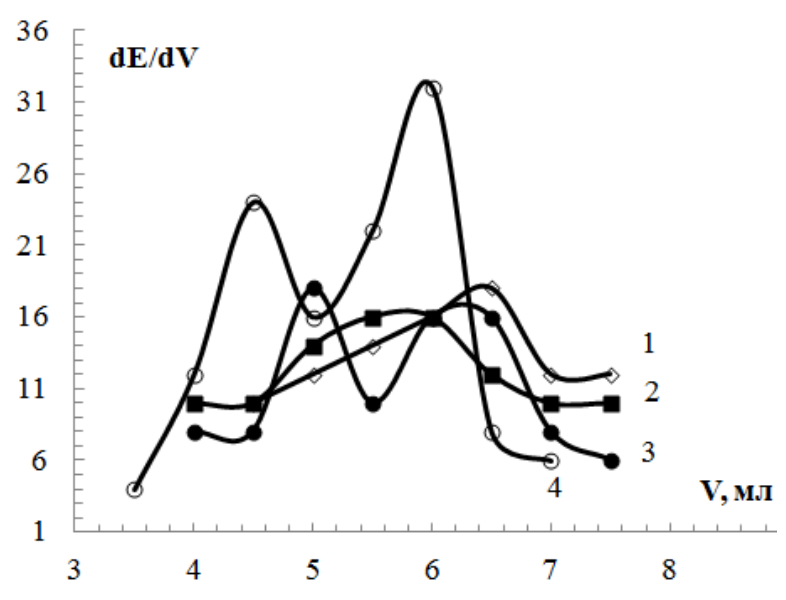

Состав и антиоксидантная активность водных настоев чая

\begin{tabular}{c|c|c|c|c|c}
\hline \multirow{2}{*}{$\begin{array}{c}\text { Название } \\
\text { чая }\end{array}$} & Тип & \multicolumn{3}{|c|}{ Содержание танинов } & Антиоксидантная \\
\cline { 3 - 5 } & ферментации & суммарное & гидролизуемые & конденсированные & активность (АОА), мг/г \\
\hline Assam & черный & 4,18 & 1,30 & 2,88 & 33,28 \\
AKBAR & черный & 5,05 & 1,55 & 3,50 & 35,00 \\
Tess style & зеленый & 6,40 & 6,40 & - & 45,80 \\
Jaf tea & зеленый & 6,87 & 6,87 & - & 47,80 \\
\hline
\end{tabular}


В таблице представлены результаты амперометрического измерения антиоксидантной активности (AОА) экстрактов различных сортов зеленого и черного чаев в пересчете на кверцетин. Как показывает анализ результатов, наименьшими показателями AOA обладают образцы черного чая («AKBAR» 35,00 мг/г, «Assam» - 33,28 мг/г) по сравнению с зелеными («Jaf tea» - 47,8 мг/г, «Tess style» - 45,8 мг/г). В зеленом чае, в отличие от черного ферментированного чая, почти полностью сохраняются все катехины и другие биологически активные вещества. Из таблицы видно, что гидролизуемые танины зеленого чая обусловливают высокое значение АОА, в сравнении с конденсированными - черного чая. С химической точки зрения это может быть объяснено, во-первых, наибольшей концентрацией полифенольных веществ, во-вторых, большим количеством гидроксильных групп в пересчете на одну молекулу, а в-третьих, отсутствием соединений хиноидной структуры, образующихся после ферментации, которые окисляются значительно слабее гидроксилированных аналогов. Между суммарным содержанием танинов и АОА для исследуемых образцов чая наблюдается удовлетворительная корреляция (коэффициент корреляции $R=0,9593$ ).

Однако в водных, а особенно в водно-щелочных средах при хранении с высокой вероятностью возможно развитие автоокислительных превращений фенольных соединений с образованием супероксид анион-радикала или пероксида водорода как результат одно- и двухэлектронного переноса на кислород, что приводит к потере антиоксидантной активности вследствие образования радикальных интермедиаторов различной природы, но и замене антиоксидантной функции на диаметрально противоположную вследствие наличия у образующихся продуктов мутагенной и цитологической активности [11]. В связи с этим было исследовано влияние кислотности среды на окислительные превращения танинов чайного экстракта как потенциальных побочных реакций непродуктивного расходования антиоксидантов.

На современном рынке имеется большое разнообразие чаев с добавками, влияющими на кислотность среды. Первой добавкой к чаю был лимон. Горячий чай с лимоном называют чисто русским изобретением. Однако существует расхожее мнение о влиянии лимона на антиоксидантные свойства чая. Одни считают, что при добавлении лимона в чай напиток теряет свои антиоксидантные свойства [10], другие - увеличивает [12].

Исследовано влияние лимонной кислоты на состав и антиоксидантную активность экстрактов чая. Выявлено, что при добавлении лимонной кислоты в экстракт зеленого чая не изменяется форма дифференциальной кривой, но наблюдается смещение максимума в сторону большего расхода перманганата калия (рис. 2). Полученная зависимость свидетельствует об отсутствии влияния лимонной кислоты на состав зеленого чая. Увеличение объема перманганата калия, по-видимому, связано с процессом окисления лимонной кислоты. Однако, как показал расчет, объем перманганата калия значительно меньше, чем необходим для суммарного окисления дубильных веществ и лимонной кислоты. Вероятнее всего, это связано с уменьшением окисления гидролизуемых танинов с понижением $\mathrm{pH}$ экстракта. При добавлении лимонной кислоты в чайный экстракт уменьшается количество ионизированных молекул полифенолов, которые окисляются в десятки раз более интенсивно по сравнению со своими неионизированными аналогами [13].

В отличие от зеленого чая, дифференциальные кривые черного чая с лимонной кислотой и без отличаются друг от друга (рис. 3). В присутствии лимонной кислоты отсутствует второй максимум, отвечающий за окисление конденсированных дубильных веществ, а первый, как и в случае зеленого чая, несколько смещен. Полученные данные подтверждают сделанные нами выводы о снижении окислительной способности полифенолов при уменьшении рН среды, так как теарубигины, входящие в состав конденсированных дубильных веществ, в кислой среде переходят в неионизированное состояние, теряют свой цвет и способность к окислению.

При исследовании антиоксидантной активности экстрактов чая при уменьшении рН среды установлено, что АОА зеленого чая практически не изменяется при добавлении лимонной кислоты (рис. 4). В случае черного чая наблюдается понижение антиоксидантной активности, что свидетельствует о большем влиянии рН среды на антиоксидантные свойства конденсированных дубильных веществ.

Таким образом, процесс ферментации, приводящий к образованию конденсированных танинов, снижает антиоксидантные свойства экстрактов чая, а повышение кислотности среды приводит к переходу танинов из ионизированного состояния в неионизированное и, как следствие, снижению антиоксидантной активности. Однако снижение АОА за счет перехода танинов в неионизированное состояние при действии лимонной кислоты следует считать временным, так как при употреблении чайного напитка и попадании его в щелочную среду кишечника происходит ионизация танинов, и они вновь становятся антиокисидантно-активными. При этом лимонная кислота, переводя танины в неионизированное состояние, защищает их от окисления кислородом воздуха и способствует сохранению их АОА в процессе хранения. 


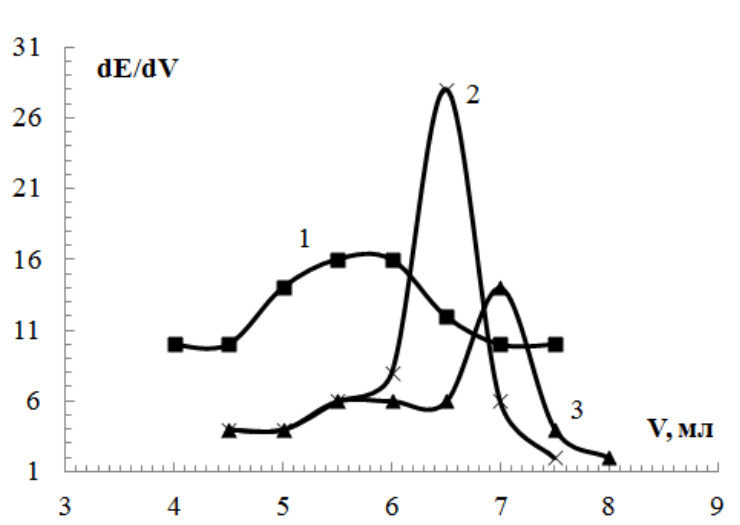

Рис. 2. Дифференциальные кривые титрования перманганатом калия ( $V$ - прибавленного $\mathrm{KMnO}_{4}$, $\Delta V$ - объем очередной порции $\mathrm{KMnO}_{4}$,

$\Delta E$ - изменение потенциала, вызванного прибавлением одной порции $\mathrm{KMnO}_{4}$ ) экстракта чая «Tess style» в присутствии лимонной кислоты и без: 1 - без; 2 - 0,5 мл 0,025 М лимоной кислоты; 3 - 1 мл 0,025 М лимонной кислоты

Рис. 4. Антиоксидантная активность водных экстрактов чая с различным типом ферментации: 1 - «AKBAR»; 2 - «Tess style» и содержанием лимонной кислоты: а - 0,5 мл 0,025 М; б - 1 мл $0,025 \mathrm{M}$

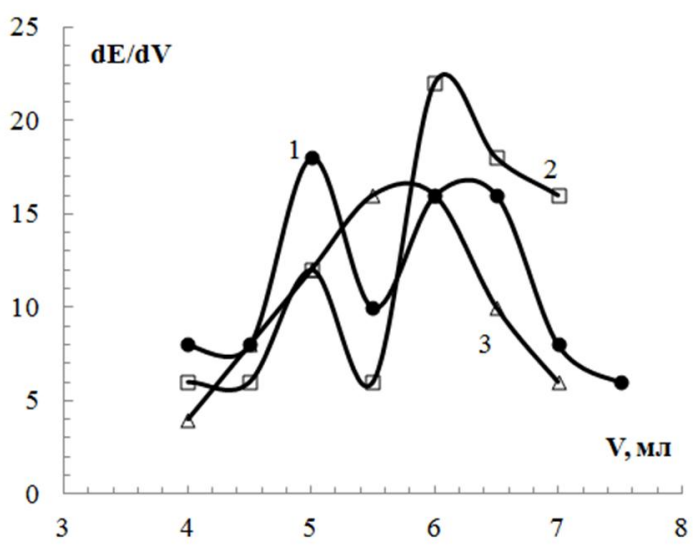

Рис. 3. Дифференциальные кривые титрования перманганатом калия ( $V$ - прибавленного $\mathrm{KMnO}_{4}$, $\Delta V$ - объем очередной порции $\mathrm{KMnO}_{4}$, $\Delta E$ - изменение потенциала, вызванного прибавлением одной порции $\mathrm{KMnO}_{4}$ ) экстракта чая «AKBAR» в присутствии лимонной кислоты и без: 1 - без; 2 - 0,5 мл 0,025 М лимоной кислоты; 3 - 1 мл 0,025 М лимонной кислоты

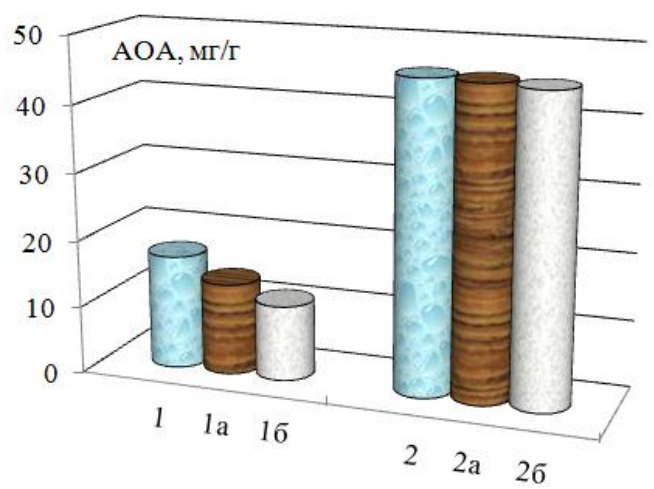

\section{Bblвodbl}

В результате проведенных исследований установлено, что зеленый чай содержит гидролизуемые дубильные вещества, а черный - гидролизуемые и конденсированные. Танины в зеленом чае составляют 6,4-6,87\%. Содержание полифенолов в образцах черного чая 4,18-5,01\%, из которых конденсированные составляют примерно $70 \%$ от суммарного содержания. Установлено, что наивысшими показателями антиоксидантной активности обладают образцы зеленого чая. Выявлена корреляционная связь между суммарным содержанием полифенолов в чае и АОА. Дубильные вещества чувствительны к кислотности среды: чем ниже $\mathrm{pH}$, тем более устойчивы танины к окислению и, как следствие, сохранению антиоксидантной активности.

\section{Список литературь}

1. Katiyar S.K., Mukhtar H. Tea antioxidants in cancer chemoprevention // J. Cell. Biochem. Suppl., 1997. Vol. 67. Pp. 59-67.

2. Sano J. Effects of Green Tea Intake on the Development of Coronary Artery Disease // Circ. J. 2004. Vol. 68. Pp. 665-670.

3. Федосеева А.А., Лебедкова О.С., Каниболоцкая Л.В., Шендрик А.Н. Антиоксидантная активность настоев чая // Химия растительного сырья. 2008. №3. С. 123-127. 
4. Гринкевич Н.И., Сафронич Л.Н. Химический анализ лекарственных растений. М., 1983. 175 с.

5. Рябинина Е.И., Зотова Е.Е., Ветрова Е.Н., Пономарева Н.И. Сравнение химико-аналитических методов определения танидов и антиоксидантной активности растительного сырья // Аналитика и контроль. 2011. Т. 15, №2. С. 202-208.

6. Рябинина Е.И., Зотова Е.Е., Пономарева Н.И. Потенциометрическое определение дубильных веществ в лекарственном растительном сырье // Фармация. 2012. №2. С. 8-10.

7. Рябинина Е.И., Зотова Е.Е., Пономарева Н.И., Рябинин С.В. Сравнительное исследование мелиссы лекарственной и шалфея лекарственного на содержание полифенолов // Вестник ВГУ. Серия: Химия. Биология. Фармация. 2009. №2. С. 32-36.

8. Яшин А.Я. Инжекционно-проточная система с амперометрическим детектором для селективного определения антиоксидантов в пищевых продуктах и напитках // Российский химический журнал. 2008. T. LII, №2. C. $130-135$.

9. Свидетельство №31-07 об аттестации МВИ. Методика выполнения измерений содержания антиоксидантов в напитках и пищевых продуктах, биологически активных добавках, экстрактах лекарственных растений амперометрическим методом, разработанная ОАО НПО «Химавтоматика», аттестованная в соответствии с ГОСТ Р 8.563-96, ГОСТ Р ИСО 5725-2002 / Федеральное государственное унитарное предприятие «Всероссийский научно-исследовательский институт метрологической службы». Дата выдачи 4 мая 2007 г.

10. Мисин В.М., Сажина Н.Н., Короткова Е.И. Измерение антиоксидантной активности экстрактов смесей чая электрохимическими методами // Химия растительного сырья. 2011. №2. С. 137-143.

11. Roginsky V., Alegria A. Oxidation of extracts and tea catechins by molecular oxygen // J. Agric. Food Chem. 2005. Vol. 53, N11. Pp. 4529-4535.

12. Барабой В.А. Катехины чайного растения: структура, активность, применение // Біотехнологія. 2008. Т. 1, №3. C. 25-36.

13. Каниболоцкая Л.В., Лебедкова О.С., Шендрик А.Н. Хемилюминесценция в реакциях окисления водных экстрактов чая кислородом в водно-щелочной среде // Химия растительного сырья. 2006. №2. С. 43-46.

Поступило в редакциию 31 мая 2013 г.

После переработки 25 сентября 20132. 
Ryabinina E.I. ${ }^{*}$ Zotova E.E., Ponomareva N.I., Mezentseva O.A., Bulgakova M.A. THE INFLUENCE OF FERMENTATION AND CHANGE IN ACIDITY OF MEDIUM ON THE COMPOSITION AND ANTIOXIDANT ACTIVITY OF AQUEOUS EXTRACTS OF TEA

Voronezh State Medical Academy after N.N.Burdenko, Studencheskaya str., 10, Voronezh, 394036 (Russia),

e-mail: ryabinina68@mail.ru

The presense of hydrolysable tannins in green tea, as well as hydrolysable and condensed tannins in black tea has been prooved with the help of potentiometric method, and condensed compounds take $70 \%$ of the total content. Antioxidant activity of tea extracts with different type of fermentation has been measured using amperometric method and determined, that the samples of green tea have the highest value of activity. Correlation between the total amount of polyphenols in tea and antioxidant activity was found. There was established, that decrease of $\mathrm{pH}$ lowers the quantity of tannins, which take part in oxidationreduction processes, what may have a connection with their transformation into non-ionized form.

Keywords: antioxidant activity, polyphenols, potentiometric and amperometric methods, tea.

\section{References}

1. Katiyar S.K., Mukhtar H. J. Cell. Biochem. Suppl., 1997, vol. 67, pp. 59-67.

2. Sano J. Circ. J., 2004, vol. 68, pp. 665-670.

3. Fedoseeva A.A., Lebedkova O.S., Kanibolotskaia L.V., Shendrik A.N. Khimiia rastitel'nogo syr'ia, 2008, no. 3, pp. 123-127. (in Russ.).

4. Grinkevich N.I., Safronich L.N. Khimicheskii analiz lekarstvennykh rastenii. [Chemical analysis of medicinal plants]. Moscow, 1983, 175 p. (in Russ.).

5. Riabinina E.I., Zotova E.E., Vetrova E.N., Ponomareva N.I. Analitika i kontrol', 2011, vol. 15, no. 2, pp. $202-208$. (in Russ.).

6. Riabinina E.I., Zotova E.E., Ponomareva N.I. Farmatsiia, 2012, no. 2, pp. 8-10. (in Russ.).

7. Рябинина Е.И., Зотова Е.Е., Пономарева Н.И., Рябинин С.В. Vestnik VGU. Seriia: Khimiia. Biologiia. Farmatsiia, 2009, no. 2, pp. 32-36. (in Russ.).

8. Iashin A.Ia. Rossiiskii khimicheskii zhurnal, 2008, vol. LII, no. 2, pp. 130-135. (in Russ.).

9. Svidetel'stvo №31-07 ob attestatsii MVI. Metodika vypolneniia izmerenii soderzhaniia antioksidantov $v$ napitkakh $i$ pishchevykh produktakh, biologicheski aktivnykh dobavkakh, ekstraktakh lekarstvennykh rastenii amperometricheskim metodom, razrabotannaia OAO NPO «Khimavtomatika», attestovannaia v sootvetstvii s GOST R 8.563-96, GOST R ISO 5725-2002 / Federal'noe gosudarstvennoe unitarnoe predpriiatie «Vserossiiskii nauchnoissledovatel'skii institut metrologicheskoi sluzhby». Data vydachi 4 maia 2007 g. [Certificate №31-07 of attestation of MM. Method for measuring the content of antioxidants in beverages and foods, dietary supplements, herbal extracts ampe-rometricheskim method, developed by NPO "Khimavtomatika", certified in accordance with GOST 8.563-96, State Standard R ISO 5725-2002 / Federal State unitary Enterprise "All-Russian Research Institute of Metrological Service." Date of issue May 4, 2007].

10. Misin V.M., Sazhina N.N., Korotkova E.I. Khimiia rastitel'nogo syr'ia, 2011, no. 2, pp. 137-143. (in Russ.).

11. Roginsky V., Alegria A. J. Agric. Food Chem., 2005, vol. 53, no. 11, pp. 4529-4535.

12. Baraboi V.A. Biotehnologija, 2008, vol. 1, no. 3, pp. 25-36. (in Russ.).

13. Kanibolotskaia L.V., Lebedkova O.S., Shendrik A.N. Khimiia rastitel'nogo syr'ia, 2006, no. 2, pp. 43-46. (in Russ.).

Received May 31, 2013

Revised September 25, 2013

\footnotetext{
* Corresponding author.
} 
